\title{
The Ethical Context of Justifying Anti-Doping Attitudes: Critical Reflections
}

\author{
Jerzy Kosiewicz
}

Josef Pilsudski University of Physical Education in Warsaw, Poland

KEYWORDS

The reflections presented in the paper are not normative (in general, it can be said, that they do not create moral values and demands). The presented reflections particularly stress the sense, essence, meaning, and identity of sport in the context of moral demands. A disquisition pointing out that sports and sport-related doping can be situated beyond the moral good and evil must be considered precisely as metaethical, and leads in a consciously controversial way to fully defining the identity of sport in general, as well as the identity of particular sports disciplines.

These reflections also refer to the issue concerning the identity of sports philosophy, i.e. general deliberations and specific issues concerning, for example, the factual and cognitive status of normative ethics in sport.

It is impossible to overestimate the role and meaning of metaethical reflection in the context of substantiating moral demands in sports as well as in the context of practical results of expectations. This metaethical reflection not only extends self-knowledge, but also contributes to the metaphilosophy of sports. The degree of the development of self-knowledge - both the metaethics of sports and the metaphilosophy of sports - is also a very important declaration, and a sign of general maturity of the philosophy of sports (Kosiewicz 2008/2009, pp. 5-38).

ethics, morality, doping, anti-doping, fair play

\section{Sport versus ethics and morality}

In philosophy, there are two basic points of view pertaining to the relationship between morality and ethics. The first one - accidental - treats these notions as analogical concepts, the second one, also common in sociology and psychology, treats them as separate terms.

Morality, in a nutshell, is regarded as spontaneous phenomenon that takes place within social relationships pertaining to diverse, smaller, or bigger social groups. Among many definitions of morality, the highly useful ones seem to indicate morality's most fundamental components that are created, grounded, and modified in everyday life, such as values, opinions, norms, patterns, models, and schema of moral behaviour. All these elements have a regulatory influence (similar to law and customs), but also an informal influence (similar to customs, but contrary to law) on social life by means of sanctions, that is, rewards and punishments, occurring spontaneously - consolidated and modified. 
Ethics, on the other hand, is perceived as the science of morality. We may distinguish its several diverse and detailed disciplines, such as: the philosophy of morality, the sociology of morality, or the psychology of morality. In each case, we are dealing with some exceptional form of ethics, even though, in the name of the given subject, the expression "ethics" does not appear. Maria Ossowska, the philosopher, sociologist, and psychologist, in her prominent work "The Foundations of the Science of Morality" (written in Warsaw during the German occupation at the time of the World War II and published right after) introduced a concept of ethics as an integrated science - constituting a unit (Ossowska 1966). The abovementioned disciplines constituted its foundations.

Religious morality or religious ethics, in turn, have a moralizing character. Both of these expressions are used interchangeably and in an informal context. Religious ethics is not a cognitive discipline, because statements within its scope are beyond truth and falsehood in a logical sense. It constitutes an element of teaching (a doctrine, if you will) of a given church, or an independent part of a religion that is emancipated from it, identical to three others, that is: cult, sacral organisation, and the mentioned doctrine.

Ethics, as one of the fundamental sections of philosophy, is also called the philosophy of morality. It consists of normative ethics, descriptive ethics, and meta-ethics - in other words, metamorality, or the philosophy of morality, but understood in a more narrow way.

Sports ethics, in turn, as a cognitive discipline referring to the rules of philosophy, is divided similarly into normative ethics, descriptive ethics, and sports metaethics. Sports normative ethics has a suggestive and evaluative character. It defines diverse rules of conduct connected with sports activities. It creates norms and behaviour assessments considered proper or inconsistent with the recommended rules. Sports descriptive ethics characterizes, interprets, and explains particular phenomena and moral relations that occur in sport. Sports metaethics deals with general problems that are more abstract and connected with the sources of moral values, their essence, sense, meaning, and relations with axiology, as well as emotional, cognitive, and social functions, and the mechanisms and ways of their manifestation (Compare: Przyłuska 1993, p. 11).

Sports normative ethics is, from the point of view of philosophy, the subject of research of descriptive ethics as well as how it inspires the search for knowledge in meta-ethics, similar to descriptive ethics.

Opponents of drugs in sports practice, more or less, consciously, apply normative ethics, indicating that it is a moral evil. Consequently, they are constructing an ethics norm - a demand for the prohibition of its use - and at the same time, a very negative opinion; an ethical judgement of the athletes who, in their opinion, break common and necessary applications of the moral imperative. The main context of explanation are with common beliefs and convictions, discretionary relative guidelines, as well as penalization in the form of a collective condemnation of athletes and people from their group who are connected more or less directly with a given case (i.e. incident, scandal, etc.), regardless of rulings in the code of criminal or administrative procedure. In such cases, the priority and prominence of moral sanctions over legal ones is accepted; in my opinion this is incorrect.

Sports normative ethics is primarily concentrated on evaluating and creating norms of conduct in sport. It is a practical part of sports ethics that does not formulate statements that could be considered true or false in a logical sense. Due to their discretionary character and relativity, the indicated norms have no scientific properties.

Within the discussed sports ethics, we may distinguish fair play value and the anti-doping rule as bases for the recommended conduct of the contestants ${ }^{1}$.

\footnotetext{
${ }^{1}$ I take no position - supported by adequate factual justification - on the use of doping agents in children's and youth sports as I am unaware of any scientific research in this scope and I don't know how harmful or advantageous doping use can be for a young athlete's body. However, intuitively, I am against such practices and I adopt a radical attitude that lacks any justification. I hypothetically (as an initial hypothesis without any
} 
In the context of it all, an argument with a moral undertone appears, indicating that the use of legal doping is a breach of the rule of equal opportunities for all athletes, because persons abiding by the rules of a given discipline have a smaller chance of achieving success than the ones using drugs. Such an argument hits wide of the mark because sports competition aims at not only showing inequality of opportunities but demonstrating and deepening - as far as possible - the real differences between competitors. This pertains not only to direct rivalry, but to the preparatory period as well. A well-thought-out foul play is used for this, since it "bends" and breaks the rules of pure play, provokes reprehensible and penalized conduct in opponents, introduces and applies it in secret from competitors novelties or even serious technological discoveries, like for example, in car racing or sailing cruises.

\section{Why can moral expectations pertaining to sport be groundless?}

In reflections on the subject of the properties of sport, and especially competitive sport, most people interested in the topic put great emphasis on its connections with practical ethics, namely on relations with presupposed and normative undertones. The role and goal of the particular ethical rules created discretionarily within sport, is the stimulation of the expectations of behaviours, characteristic spontaneous reflexes, whose purpose would be the realization of intuitively and situationally perceived goodness. It can be found, according to subjective feelings of people who, under the inner inspiration, deal with moralizing, at the bottom of the regulations of a given discipline, objectified game, or the whole sports activity. The indicated relation and possible central location of goodness within sport, bears, according to the supporters of the prominent role of morality in sports, a blatant testimony to the human spirituality and metaphysically and axiologically unquestionable spiritualization of sport (Kosiewicz 2099, pp. 79-88).

In their opinion, this authorizes the necessity for the realization in sports external relations (which is difficult to define), in connection with the subject, hypostatic: ethical and esoteric properties, originally located in some unidentified, abstract space outside the subject (for example, in a characteristic for Mircei Eliad's views to universal spiritual center called by him the pre-established centre of religion, (Eliade 1997, Kosiewicz 1998, pp. 277-283). This pertains to those moral and spiritual values, which are closely connected with human nature and social functions, and influence entities and groups engaged in social interactions. This may lead to at least dual explanation, as presented below:

1. It can be assumed, in agreement with Eliade's concept, that a universal, transcendental, spiritual center exists, which may influence (due to its unilateral dependence understood as the source and cause of inspiration) psychological human characteristics, such as spirituality or spiritualism (Kosiewicz 2009).

2. Another argument may relate to Kant's justification of the metaphysics of morality, which indicates that the noumenal world has irrefutable moral rules that every human being is obliged to obey. In relation to this, Kant points to a metaphysical source of morality - "the starry skies above" him and above every other subject - from which all moral law stems and where it is placed. As every human mind exists in this noumenal or abstract world of ethical rules, each individual mind also experiences, as Kant describes, "the moral law inside me", an inner life in

rational or scientific reasoning based on cause-and-effect relations) assume that the use of doping can be harmful to the health of children and youth.

If ever it is proved without any doubt that all forms of doping are harmful for adult athletes, in my opinion, it will not be a sufficient argument (either substantially or logically) to imply that doping is also dangerous to children and young people, i.e. without adequate empirical studies, the claim about the harmfulness of doping is only an intuitive initial hypothesis with no empirical justification.

As I am not ruling out the possibility of the occurrence of destructive effects on young bodies (see my brief disquisition with an article by Mike McNamee 2009, pp. 111-126), I would advise against repeating dopingrelated experiments on children and youth, such as those which were conducted in the German Democratic Republic and in the Soviet Union. 
every subject. Hence, a single and unique synthesis creates an essential connection of what is objective and transcendental with what is subjective and immanent. The synthesis is an interiorization of a moral norm, its description, and metaphysical justification in a universal form and, at the same time, multidimensional rule of ethical behaviour with an intuitive and individual indicator of conduct.

In Eliade's philosophy, we deal with an intriguing, but to some extent phantasmagorical hypothesis of a spiritual center, which presumes a moral center and yet is without a solid foundation of justification. However, Kant's justification of the metaphysics of morality includes more essential argumentation, rooted in solid philosophical ground delineated in epochal The Critique of Practical Reason (Kant 1984a) and its simplified edition, The Groundwork of the Metaphysics of Morals (Kant 1984b). Despite this, Kant's explanation referring to metaphysics has a significant flaw with ontological and epistemological overtones. This fallacy is enough to debunk the objectivity, necessity and universality of intellectual rigor, and ethical formalism as put forth by the philosopher himself. The final grounding of Kant's metaphysics of morality rests on the assumption that God exists. Kant claims that, nobody is good (a prototype of goodness), apart from God (who you cannot see). Hence, what is the source of the concept of God as the highest good? It only stems from an idea, which is created by the mind a priori about moral perfection and is inseparably linked with the notion of free will (Kant 1984b, p. 32).

According to Kant, it is the irrefutability of this final premise (from the point of view of the methodological sciences; Ajdukiewicz 1985, pp. 287-313), that he is unable to prove. An ontological mistake - a shortcoming or misuse of facts - indicating that God exists, though, Kant as a philosopher, cannot prove such certainty. Though philosophy has its own research methods, they are not sufficient in this respect. Kant cannot prove God's existence in a certain, essential, and definite way as well as justify the universality and indisputability of metaphysical assumptions, that is morality, on God's existence $^{2}$.

\footnotetext{
${ }^{2}$ Both in independent philosophy and in confessional orientation, there are, roughly speaking, two ways of arguing for the certainty of God's existence, i.e. a cosmological way and anthropological one.

The first way refers to Aristotle who attempted to prove the existence of God on the basis of the extraspection method, i.e. the reception of nature - the Universe. In short, he implied that there is the First Mover, the First Cause, or the God-Mind. The anthropological argumentation comes from direct introspection or intuition, regardless of the empirical experience, the sensory perception of nature. Incidentally, such arguments, which were also shared by Thomas Aquinas and others, turned out to be insufficient even in terms of classical logic, i.e. Aristotelian logic. Even the famous Stagirite and others, including Thomas Aquinas, were unaware of the above
} mentioned fact.

The second way entails, for example, Plato (and followers of his philosophical approach) who, following, among others, Pythagoras and the Pythagoreans (the supporters of the Tetraktys), argued that the abstract world (the cause of the Universe) exists on the basis of the introspective experience, i.e. on the basis of an internal, subjective, intuitive, and direct observation (independent of induction). According to Plato, based on ideas, i.e. general forerunners of things, the Demiurg created ideal nature which is at the same time prone to degradation. Such argumentation, i.e. an anthropological justification that is connected with probing into one's own soul or the thinking ego, was carried on by Aurelius Augustine and Descartes among others.

It also concerns such contemporary Jewish, Catholic, and Protestant philosophers as Martin Buber, Emmanuel Levinas, Peter Wust, Gabriel Marcel, or Stanisław Kowalczyk. They all stress that philosophy does not indicate with absolute certainty that God exists in either cosmological or anthropological context (Kosiewicz 1999, pp. 13-38).

In the conclusion of the context of cosmological justification, Aristotle unintentionally performed an intuitive and hypothetical action. In short, he stated that the existence of nature proves the existence of God as the cause. Aristotle's empirical argumentation was and still is insufficient (which he never realized). He acted in a way typical of speculative philosophy. Within the range of the issue he studied and at the end of the chain of inductive reasoning, Aristotle developed a typical metaphysical hypothesis justifying the real existence of hypostasis.

As far as the case being discussed is concerned, the difference between Aristotle and Plato was that the former explained the functioning of nature by claiming that based on its existence one can argue the existence of its divine Cause and divine Mover. On the other hand, Plato and the supporters of his philosophical approach 
Moreover, Descartes contended with a similar problem. In his philosophy of metaphysics, anthropology, and epistemology, God (that is the idea of God) also constitutes the final guarantee of the existence of the objective world and the certainty of its cognition. Descartes claimed "God has endowed each of us with some light of reason by which to distinguish truth from error" (Descartes 1981, p. 32) and that, the very principle that those things which we conceive very clearly and very distinctly are true, is guaranteed only because of the fact that God is or exists, that He is a perfect being, and that everything which is in us comes from Him. From that it follows that our ideas or notions, being real things which come from God, to the extent that they are clear and distinct, in that respect cannot be anything but true (Descartes 1981, pp. 45-46).

Unfortunately, God's existence is impossible to explain and justify philosophically in an indisputable manner, neither a priori nor a posteriori. Aristotle and Thomas Aquinas also tried to prove God's existence basing their arguments on premises of outer experience (cosmological, i.e. empirical and concerning the nearest or farther nature) and speculation, but with no success.

Taking into consideration the above investigation, it might be stated that the conviction that particular moral principles are innate or universal, as well as the conviction that such principles should be applied, may be based on the assumption that God exists; however, this assumption is not enough and not inherently irrefutable due to the doubts concerning God's existence. It can not be explained in any way, apart from an extraordinary gift of subjective, intuitive conviction (a particular, direct belief, ethical mission or moral crusade encompassing both close and distant social environments), or exceptional properties of any subject. Such uniqueness or exceptionality cannot also be explained in any doubtless, objective, definite, or universal way.

These justifications confirm neither the universality of any enforced moral principles, nor the necessity of their absolute application. In my opinion, it also refers to general moral principles in sport, as well as to more specific values such as fair play or anti-doping attitudes.

Alasdair MacIntair noted:

the unsolvable nature of many of contemporary endless moral disputes is caused by heterogeneous and incommensurable concepts included in the premises on which the participants of these debates argue among themselves (MacIntaire 1996, p. 403).

The conceptual melange deepens for instance when the discussion regarding moral philosophy includes the popular arguments of only quasi-philosophical overtones.

To elaborate on the relationship between spirituality and morality, adherents to such relationships experience that one particular expression of such spirituality is not only introducing ethical values into sports activities, but also revealing that moral principles are a source of and indispensable, basic, and obvious inspiration for any sports activity. Without such a relationship, sport loses not only its meaning, but also its existential foundations and the possibility of an ethical and didactic influence on the people creating an image of "sport" (mainly coaches and competitors) and its viewers.

"Sportsmanship as a Moral Category," text by James W. Keating, already a classic in the field and reprinted several times $(1964,2001,2007)$ might serve as an example of the approach which, being noble in its motives, strenuously tries to saturate and raise value of sport by adding to sport ethical properties. The author refers to, among other things, quotations from speeches by Albert Camus (the Nobel Prize winner for literature in 1957), Edgar Hoover (former U.S. president), Doctor Robert C. Clothier (former President of Rutgers University), Henry S. Commager (Professor of History at Columbia University), Lyman Bryson (of Columbia University), Charles W. Kennedy (Professor of English Department at Princeton University), and Pope Pius XII (Keating 2001, pp. 7-9).

explained the beginning and functioning of the Universe by referring directly to the supernatural world (and not referring to natural science-based research) as the only real one that constitutes the real cause of the existence and functioning of the Universe. 
All the statements quoted by Keating, however, have a clear common sense and everyday meaning. These statements can only indicate (it is worth noticing that the choice of the quoted people was indeed intentional, but totally unrepresentative), that some important figures from public life attributed participation in sport and sporting competition with the ethical properties inherently included in this type of activity - it is worth noting that the choice of the quoted people was indeed intentional, but totally unrepresentative. These statements do not create a context sufficient enough for justification (to be exact, they don't justify the authors' conviction at all in the terms of classical logic, and in particular in syllogistic), because they do not constitute substantive evidence to draw the conclusion indicated by Keating. The thesis that sport is actually implemented with moral properties cannot be justified on the basis of the opinion of several appointed people. On the basis of those quotes from the common statements of people, who - with the exception of Albert Camus - are not professionally engaged in ethics (e.g. philosophically, sociologically or psychologically), the logically and factually correct conclusion that sportsmanship is a moral category cannot be drawn.

For example, Keating writes that Camus (a prominent existentialist who considered many ethical issues) claimed, "that it was from sports that he knew about ethics", (Keating 2001, p. 7). It seems obvious that Camus wanted only to valorize sport in a courteous manner. It would be quite naïve to treat this statement as an indisputable truth. Apparently, as it turned out, Camus did not foresee such a possibility. If he could answer, he would most likely turn it into joke and, as a comment, he would certainly have written, paraphrasing the refrain of this funny song: "I am fool, but not that stupid. Maybe stupid, but not so much fool."

Incidentally, not every statement of the philosopher is a philosophical statement - that is philosophical in the strict sense - especially when he speaks condescendingly and without obligation. Unintentional and colloquial statements "could happen" even to brilliant philosophers in their great works. With such an objection - and it was a serious allegation - Martin Heidegger accused Hegel, when the latter considered the properties of time and its relationship with the entity ${ }^{3}$.

Keating also cited Hoover, who reportedly stated that, "next to religion, the single greatest factor for good in United States in recent years has been sports," (Keating 2001, p. 7 - by Leahy, 1951, p. 198). The statement is based only on subjective, very superficial insight of a former U.S. president. None of the concepts used in the statement were identified, defined or tested, which is described and explained not even in an ordinary sense (not to mention scientific sense). This sentence is anything but serious in the sense that cognition could be deduced beyond the understanding that Hoover was referring kindly and with appreciation to sport and had expressed such an opinion. We do not know how he understands religion, how he understands social and ethical characteristics of sport and, finally, what he meant by using the concept of good and of what relationships or correlations did he think occur between these phenomena that are ambiguous and not defined by him.

No wonder that the significant role of morality is indicated in human relationships, because only humans, unlike animals, have such higher and conscious emotional needs. However, it does not mean that all spheres of human activity, including sport, should be imbued with morality or governed by it. In many spheres of life, morality constitutes neither a primary nor a direct aim, and it is not or should

\footnotetext{
${ }^{3}$ Heidegger aptly noted that, "while interpreting time, Hegel moves toward popular understanding of time" (1994, p. 601), when he argues that (1990, p. 258):

Time, as the negative unity of self-externality, is similar to an out-and-out abstract, ideal being. It is that being which, inasmuch as it is, is not, and inasmuch as it is not, is: it is. Becoming directly intuited; this means that differences, which admittedly are purely momentary, i.e. directly selfsublating, are determined as external, i.e. as external to themselves.
}

Hegel's description of time, the German hermeneutist writes in his long disquisition, assumes on the basis of "now" that the latter remains covered and equalized to be observed as something "ideally" present (1994, p. 601).

In contrast with Hegel, all the discussed classical concepts of existence and time have nothing in common with their popular interpretation, even those including the idea of the Absolute which was brilliantly developed and presented by the German idealist at the beginning of the $19^{\text {th }}$ century (Kosiewicz 2010, p. 182). 
not be taken into consideration at all. Pragmatic, social, as well as legal regulations and sanctions, general and specific (i.e. criminal, civil, and administrative), are sufficient in this respect. Sports activities fall into this category.

I assume that associating sport with morality stems from a spontaneous inclination or even an intuitive and emotional necessity to interpret this sphere of social activity in the context of spiritual needs. Probably, it is stimulated by a conviction that sport, which nowadays is regarded as a form of mass culture, should be indispensably appreciated in this way. Meanwhile, high-performance competitive sport, spectator, professional, or Olympic sport significantly fills and imparts its assumptions to the cultural sphere on the local and global scales with spectacular actions and events. Direct transmissions, reports, and commentaries reach almost simultaneously or with a slight delay almost every corner of the globe thanks to huge stadiums, large halls, and other sport arenas, as well as electronic and non-electronic mass media. Professional sport is becoming popular on a mass and unprecedented scale, and demand for its products is still increasing. Nowadays, no one needs to be strongly persuaded that sport has exceptional and distinguishing properties on its own, without attributing to it values incoherent with its kind (which is based on and governed by rules of a particular discipline). Sport in itself is absolutely sufficient and nothing needs to be additionally ascribed or attributed to it. Sport is complete as it is. No additional attributes need to be added or ascribed. Any moral stimulation is needless - including religious, political or ideological stimulation.

\section{The relationships between sport and morality, and between fair play and doping}

When considering the relationship between professional sports and morality, three main outlooks can be distinguished:

1. The first outlook assumes significant recognition of morality - morality has supreme function in relation to sport. Thus, sport in this approach is perceived as subordinate and subservient in relation to morality; sport should primarily be a carrier of ethical values. This viewpoint indicates, among other aspects, that people associated with sports activities, particularly athletes, have a unique, sophisticated, and extremely important moral mission - although they might not be aware of it or they may not share this view - the mission that requires spreading wherever possible, whether in business or in private environment, an unspecified moral good. Preachers of this point of view can be characterized sometimes - as I have noticed - by an unconcealed and an unyielding tenacity that characterizes a possessed priest-zealot who does not tolerate any opposition, and is absolutely convinced of the inalienable need to promote and even impose his own beliefs and moral standards as a universal, a necessary, and an objective law. It does not include Western authors, in particular representatives of the English-speaking countries, balancing their own opinions and related points of view.

2. The next point of view assumes an additive - in relation to the rules of the game - a complementary function of morality. Morality in this approach may serve, though not necessarily, to strengthen the proper course of a game.

3. The third outlook totally rejects the need for moral principles in sport. The rejection of moral principles according to this approach is based, inter alia, on the fact that the existing regulations of the various sport disciplines, and that the relevant legal provisions, are adequate in this regard.

Within the ethics of sport, particular emphasis is given to adherence to ethical assumptions, to the so-called practical guidelines of this part of ethics that are known as normative ethics. Unfortunately, such an approach excludes the understanding of ethics as a cognitive subject of philosophy, sociology, or psychology, and in particular the recognition of ethics as the subject of metaphysical reflection.

Within normative ethics, the most important role is played by the principle of fair play and the anti-doping stance. Incidentally, based on the presumption that values fair play, a negative attitude towards the various forms of doping, those that are prohibited by the relevant 
international and national anti-doping committees, as well as these newly emerging, is also displayed. This negative attitude refers to those substances that when used may not only increase the chances for success, but can possibly endanger the health of its users. Also, it is claimed that the use of such substances is immoral, because such action acts against the principle of fair play, unfairly - compared to rivals - increasing the chances of winning that is derived from doping.

Although the humanistically oriented European Fair Play Movement, and its equivalent in the form of the national fair play unions, holds negative attitudes toward prohibited forms of doping, the anti-doping institutions are completely independent from these organizations. This is mostly due to the physiological, medical, and social overtones of the anti-doping institutions. This shows, inter alia, that the issues relevant to fair play and issues related to doping in sport are autonomous; that their conceptual ranges cross rather than overlap; and that anti-doping considerations are not encapsulated by the concept of fair play, and are thus not an inherent part of the wider concept of fair play.

It is worth pointing out that, just as in relation to the importance of morality in sport, so in relation to the principles of fair play and the issues surrounding anti-doping, several different positions can be enumerated.

In considering the place fair play has among other values of sport, at least six approaches can be distinguished:

1. The first one assumes absolutization of fair play properties. It is associated with the view that the principle of fair play is the highest value of sport. This position is characteristic of most Polish theoreticians and practitioners related to sport, and physical culture in general. This includes the view of Z. Żukowska, which also highlights the educational functions of fair play. R. Zukowski, in turn, argues that the principle of fair play is the highest value of Olympism.

2. The second approach is presented by William J. Morgan, who claims that the principle of fair play is now widely understood not only as a pivotal, or cardinal quality - a basic postulate of sports behavior ("The notion of fair play speaks not just to a moral feature that is widely thought to be pivotal to the conduct of sports..." [Morgan 2007, p. 2, Shneider \& Fan Hong 2007, p. XII]) - but also a fundamental principle of behavior applicable to all kind of forms of American life ("but widely thought pivotal to the conduct of American life in all its various forms - which goes a long way toward explaining why sport has the strong hold on the American national psyche that it does" [Morgan 2007, p. 2, Schneider \& Hong 2007, p. XII]). It does not indicate (although it cannot be ruled out) that he understands fair play as the most important value of sport in general. I think that Morgan's stance in this case is aimed, rather, to emphasize that fair play is immanent, and yet a basic feature of sports activities. Incidentally, it is worth underlining that fair play surely isn't (despite the prevailing view that it is widespread in the West in this respect) a universal quality. If only because: a) the nature of the ancient Greek Olympic Games - the cordial value of Olympic Games was the religious sacrum, b) Far Eastern martial arts do not apply, as the idea of fair play is foreign to them.

Morgan also distinguishes three important aspects of fair play, indicating that fair play: a) is affective - in a mutual relationship - for all participants in competitive sports ["Fair play as reciprocal regarding the interests of individual participants in sport" (Morgan 2007, p. 2, Schneider \& Fan Hong 2007, p. XII)], b) obliges one to comply with the rules of the game ["Fair play as what Butcher and Schneider (2007, pp. 127-131) aptly called 'respect for the game'" (Morgan 2007, p. 2; Schneider \& Fan Hong 2007, p. XII)], c) is mainly (it isn't indicated that it is exclusively) has the impact of the idea of fairness (ideal fairness). Morgan regards ideal fairness as an idiogenetically conditioned moral instinct that is characteristic - as he writes - only for the American people and other English speaking nations (Morgan 2007, pp. 2-3). It influences not only the shaping of the principle of fair play and conduct accordingly to fair play guidelines, but also, in a similar way, shapes the idea of fair dealing, fair outcome, or 
fair trial (Morgan, 2007, p. 3).

Morgan explicitly presented the two aforementioned aspects. The third one is presented implicitly. It can be inferred from the following quote:

"My focus on fairness in this regard is not an autobiographical quirk but a national and cultural one. By that I mean that the ideal of fairness in its many interactions (for example, fair play, fair dealing, fair outcome, fair trial et cetera) is a way of moral thinking Americans almost instinctively entertain when they reflect on their characteristic social practices and institutions, though one they share with the members of other English-speaking nations. What is more, it is also characteristic feature of American sporting life, which is why most Americans get their first lessons on how to treat one another fairly early on they sporting lives, and continue to draw inspiration from, and be guided by, its moral descriptions well into their adult sporting lives, both as participants and spectators" (Morgan 2007, pp. 2-3).

Morgan's claims might lead to the supposition - perhaps justified - that the idea of fair play is for him nonetheless the principal determinant of competitive rivalry, and that it takes precedence over the provisions of a particular sport. It also might induce, inter alia, the assumption that Morgan identified the so-called pure game ('pure' as the game is conducted according to the regulations of a particular sport) with fair play - that is, the game conducted accordingly to the moral assumptions that are external to the rules of the game.

William Morgan's point of view doesn't show - as in the first approach - a clear apotheosis, that is, the absolutization of the fair play moral standards over all values present in sports, regardless of its form, time, and culture. He doesn't emphasize that fair play is the highest value in sport, but he points to its pervasive applicability, even in non-sport relationships. There is, therefore, on the one hand, admittedly small, but important in terms of quality, reductionism, when compared to the first outlook listed above. On the other hand Morgan extended the capabilities of fair play to make social impact. This last assertion may arouse some dissonance, because - from the standpoint of sociology, social psychology, social philosophy, pedagogy, as well as assumptions specific to organization and management - it is not advisable to examine, describe, explain, understand, and value human relationships exclusively based on determinants that are characteristic for the ethos of game, both in a moral sense of game and in a pragmatic sense (associated with the game theory). It is also advisable to be restrained and cautious when thinking about the objectification and universalization of the principle of fair. If only because of a relativistic substrate of soteriological ethics that underlies the behavior of followers of various religions, or due to the Far East's - different from the West's - moral standards. For example, the stone tablets don't include fair play in the Ten Commandment; neither does the Bushido Code.

3. Another approach points to the still effective but declining importance of fair play nowadays. This less absolutist position is presented by several authors from countries in Central and Eastern Europe, including L. Donskis. He believes that "the world of sports is simply based on Fair Play" (Donskis 2005, p. 5). Some supporters of the European Fair Play Movement shared this view. For instance, J. Palm, who indicates "The idea of Fair Play has an important role in Sport for All." (Palm 2004, p. 1), that in this kind of sport, in Sport for All, fair play is the main task ["And I insist that Sport for All presents a major task for the fair play movement" (ibid)]. Another author, H. Digiel, claims, "The principle of Fair Play is still valid" (Digiel 2004, p. 7).

4. The next approach recognizes the principle of fair play as old-fashioned, but still merits attention. This outlook is associated with S. Loland, who points out the historical conditioning, and already somewhat anachronistic, properties of fair play. At the same time, however, he stresses that fair play means more than an old-fashioned, gentlemanly, Coubertin idea; that is, it still has current value ["The ideal of fair play can prove its status as something more than a historical anachronism: as topical ideal" (Loland 2002, p. 102)]. 
5. The fifth stance perceives fair play as an anachronistic legacy of Don Quixote, a heritage of noble, naïve, and utopian values of the $19^{\text {th }}$ century and the age of Coubertin. Although Digiel and Loland are not alone in the belief that fair play, even in today's sport, plays an important function, but in Anglo-Saxon literature, the prevailing approach is that fair play is too archaic in relation to the current competitive sport; that it is the legacy of Don Quixote and a manifestation of a noble and utopian naiveté - moral errantry (L. Donskis 2005, pp. 4-5). R. Renson points out after L. Allison (Allison 2001) that adherence to fair play in sport has become evidence of the survival of the anachronistic concept that is characteristic of amateur sport ["Fair play become an anachronistic survival of the amateur sport ideal" (Renson 2005, p. 3)].

6. The last approach denies the presence (the need of existence) of moral principles in sports, including the idea of fair play. I want to emphasize that I represent this point of view. Not only do I not share the opinion and the related arguments indicating that the principle of fair play is the highest value in sport (it has never been one, and will not be) (Kosiewicz 2005, pp. 363370), but I also think that the concept of fair play is completely unnecessary; that core activities associated with fair play might be as well set by provisions of a particular sport, not by moral principles. Moral principles are not organically, substantially, or by identity bound to sport (Kosiewicz 2010b, pp. 21-29).

In the relationship between illicit doping and morality three stances can be distinguished: two extreme and one moderate. Again, we have the situation similar to the two aforementioned approaches regarding the relationship between the normative ethics of sport and the role of fair play in sport again we are dealing with one intermediate position in relation to two extreme options. These viewpoints are as follows:

1. The rigorous-restrictive approach that assumes that the use of illegal doping is mainly an unethical phenomenon, and that moral sanctions should be imposed on users of dopingregardless of the codes for civil procedures, criminal procedures, and administrative procedures. According to this point of view, doping is an unsuitable behavior for sportspeople, and also unfair one; it bears sign of fraud from the perspective of law, the rules of the game, and rivals. This stance, among others, is represented by William Morgan, who claims that the use of doping in sport is not a fair proceeding, and therefore, according to him, pursuit by the United States Olympic Committee (USOC), United States Anti-Doping Agency (USADA), as well as World Anti-Doping Agency (WADA) to stop this practice is justified, responsible, and reasonable ["I want to begin with doping itself to establish, that it is indeed unfair practice, and thus that the USOC and USADA are morally justified in trying to stop it" (Morgan 2007, p. 8)].

With regard to above, it can be indicated that activity in competitive sports aims at demonstrating superiority in a rivalry, not superiority in the application of moral rules. Sports tournaments do not present the results of the achievements in the field of normative ethics. In this matter there are no objective categories, no competition, no universal way of measuring or presenting the relevant rankings, no tables of moral achievements, and no national, continental, or global records. Today's competitive sports, highly qualified spectator sports, Olympic sports, and professional sports aim, in a strictly pragmatic way, to achieve success in the broad sense of this concept. It is advantage and benefit that matters, rather than autotelic values. The latter can be identified and recommended only under the condition that they are instrumental and useful in particular stages on the way to the intended, utilitarian (not autotelic) goal. It is normal procedure regardless of the concomitant circumstances, whether technological, moral, healthrelated, or regulatory. All of these circumstances are subordinate and secondary, and might be considered, at most, as a useful means of achieving success.

Success in the indicated sports above is determined by effectiveness that is the application of means, which help in achieving the intended goals. The application of the principle of fair conduct - much like the application of standards that are characteristic for fair play - does not bring results. If doping is prohibited by law, then it is under legal jurisdiction, and can only be 
fought with legal instruments. The ethical attitudes in this respect have no objective meaning, as moral standards have subjective, relative, occasional, or situational qualities, meaning neither objective nor universal. Whereas administrative, civil, and criminal codes of conduct in democratic countries (in terms of the assumptions adopted by them) act out of necessity, universality, and without exception (blind) - they bind a society in which they are established legal penalization acts more effectively, both preventively and as a deterrent, than any potential moral sanctions having various and relative overtones; overtones that depend, inter alia, on the cultural, civilizational, religious, political, racial, national, ethnic, economic, historical or geographical priorities. As such, moral sanctions depend on someone's point of view - that is, on an intuitively understood concept of good - and can be denied, tolerated (e.g., on the basis of silent agreement), or even recommended.

2. The second, moderate approach allows for the use of forms of performance enhancing drugs, which have not been banned yet, because they have neither been detected nor defined by antidoping laboratories. It is also assumed that certain pharmacological substances ingested by healthy individuals have the qualities of doping. Although these substances not only cure but also stimulate, the use of them is allowed in cases where athletes have health problems. Such a situation is observed among Norwegian cross-country skiers, who take medication for asthma.

3. The third stance envisions the legalization and popularization of sports doping. It proposes treating doping as unconcealed adjuvant used in close cooperation with medical centers and laboratories. This would allow for the individualization of doping programs that would be tailored to the needs and characteristics of a particular person, programs that would allow for the control, rational testing, and constant monitoring of the competitor's physiology of effort. Such conduct will result in the constant maximization of health security in the context of optimization of athletic performance.

This point of view corresponds, to some degree, with the standpoint of Claudio Tamburini (2007, pp. 23-35). He states that prohibition of using doping relatively frequently is rooted in the belief that: a) it is detrimental to the players' health; b) the practice is unfair in relation to other athletes who don't used doping, since they don't have equivalent opportunities and capabilities to compete with the players who use doping; c) it is against the "nature" and "spirit" of sport, according to which the athlete must strive to win using the natural physical abilities and qualities of character, and without the aid of artificial stimulators (Tamburini 2007, p. 24). Tamburini commenting on the phenomenon of doping, states that, among other things, doping is not only compatible with sport, but - even more importantly - "incarnates the true spirit of modern elite competitive sports" (ibid.).

Paradoxically, the third stance seems to bring the clearest, most transparent, and honest intentions, assumptions, and related objectifications. However, such outlook may also awake a multidimensional opposition, including fundamental and emotional resistance to a rational context that justifies doping. The approval for the third point of view may ensue, among other things, from the following facts:

1. A moderate stance does not provide a clarification with regards to an application of drugs and possible legal and moral anti-doping sanctions.

In the case of Norwegian cross-country runners in Winter Olympics in 2010, before, during and after the competition, the legal and not the ethical aspects were the main focus. Such approach was undertaken in a view of the immediate and tangible benefits of competition, not because of a moral prestige. The argument that, Norwegian athletes were not playing fair to other contestants, was ignored. Therefore, the statement that "the Norwegian attitude to doping has always been clear" (Gilberg, Breivig \& Loland 2007, p. 158), may raise reasonable doubts. This also applies to later statements in which Runar Gilberg, Gunnar Breivig, and Sigmunt Loland stated: "The use of performance-enhancing substances has not been publicly acknowledged by anyone. Norway is called 'the homeland of preambles' and has adjusted to a self-defined role as 
a moral leader with regard to sports ethics in general and the attitude to doping particularly"(Gilberg, Breivig \& Loland 2007, p. 158.)

The approval of the third stance would minimize the need for use of the hidden pharmacological doping - incompatible with the principle of fair play and legal presumptions (as in the Norwegian cross-country skiing). This kind of doping is officially sanctioned by the international sports associations, anti-doping institutions, and supported by legislation and the Norwegian authorities.

Such an approach does not sufficiently prevent the charge of the ethical ambiguity or discretionary axiologization inspired by and dependent on immediate needs and benefits, which was presented by competitors from other countries and their environments. On one hand, Gilberg, Breivig, and Loland emphasize that the attitude of Norwegians who are interested in sport has always been morally pure ("The Nowegian attitude that has always been clear", Gilberg, Breivig \& Loland 2007, p. 158), that is unquestionable; that they always have been moral leaders in the sport ethics, in particular, they always have been critical towards doping ("moral leader with regard to sports ethics in general and the attitude to doping particularly" [Gilberg, Breivig \& Loland 2007, p. 158 ] $)^{4}$. On the other hand, they ignore the ethical context of the situation, (which is as they claim, important for them) stressing that, sport practice is primarily anchored in the grounds of administrative law - before being grounded in the moral prohibitions and orders. The Norwegian attitude towards the situation seems to solidify mainly due to the current success of Norwegian cross-country runners, who more or less suffer from asthma. Therefore, the Norwegians associated with cross-country skiing would confirm - either intentionally or unintentionally - that even in case of doubts and reservations in the field of normative ethics, and especially with regards to moral anti-doping principles, the evaluation of the athletes' competitive achievements depend primarily on legal settlements. Less important issues, such as moral ones, can be adjudged later and only based on legal statements. The practice of sports shows that not only it is a fact but also that it should be a normative procedure in sport. The moral principles with rigorous, paternalistic or universalistic overtones appear to be the regulative composition, which is increasingly obsolete and full of dissonance, and is not compatible with the teleological conventions of contemporary sport.

\footnotetext{
${ }^{4}$ The belief about Norway's uniqueness and leadership in respect of obeying normative postulates of ethics in sport, and especially anti-doping guidelines, may raise doubts because of, at least, several reasons: a) no moral rivalry was conducted in this respect either in Europe or worldwide, b) no ranking list was introduced, c) no sociological research was designed and consequently there are no findings to disseminate such conviction as an objective and binding statement, d) such belief is undermined by anti-asthmatic therapy of Norway's female cross-country skiers participating in the Tour de Ski.

A similar situation occurs in Morgan's piece of writing where he indicates his firm conviction (like Gilberg, Breivig, and Loland motivated by noble impulses) that representatives of the American nation and other Englishspeaking nations are particularly predisposed to highly moral behavior based on honesty, objectivity, and ideal fairness motivating them, not only in terms of sport, to follow the principles of fair play. He stresses that unlike other non-English speaking nations, they have a specific moral instinct that influences their conduct. This conviction may raise doubts because of the following reasons: a) as far as I know, there is no reliable comparative research referring to the psychology of morality and the sociology of morality, either in terms of ideal fairness or in terms of the fair play principle, b) the conviction about an exceptional ethical sensitivity of American and other English-speaking peoples may raise doubts in terms of penitentiary system (especially in the USA) and from a sport point of view - in the light of doping scandals with the Canadian sprinter Ben Johnson and the American athlete and basketball player Marion Jones.

In connection with the above, it can be added that a priori conviction of representatives of a population (of a nation or a country) about their absolute superiority over others in a particular sphere of activity is a parochial phenomenon which unfortunately occurs even among great philosophers. For example, Georg Wilhelm Friedrich Hegel argued in the philosophy of the state that its top exteriorization, i.e. one of the forms of social awareness of the self-realizing Absolute (being a sign of the divine idea existing on the Earth), is the Germanic period and related institution of the German state. Friedrich Nietzsche, on the other hand, was more careful in formulating his opinions in this matter. Compared to Hegel, Nietzsche was more critical toward the above-mentioned country's culture, ideology, tradition, behavioral values, bourgeois morality, and religion. The $20^{\text {th }}$ century holocaust irretrievably undermined the legitimacy of the German idealist's well being.
} 
The Norwegian approach confirms the supremacy of legal norms over morality. Legal regulations are stronger. The strength of ethical counterarguments has less impact, especially if it generates fewer benefits. The supremacy of law over morality is authenticated - from the standpoint of the discussed example - by the approach towards doping, which expresses a need for the legalization and popularization of sports doping. This approach would also prevent health, moral and legal dilemmas related to Norwegian and international sport; would enable other athletes to share the Norwegian athletes opportunities.

It is worth noticing that the superiority of legal standards over moral rules in evaluating the behaviors of those who are involved in sports rivalry in the considered range does not automatically lead to the legalization of doping. But the legalization of doping can contribute to strengthening the rule of law over discretion and relativism of sport ethics.

To summarize the above statements, I would like to highlight that the views presented by the Norwegians associated with cross-country skiing confirmed, or are consistent with, my idea (as well as, in a way, with Frederick Nietzsche's theory, 1912), that sporting events take place beyond moral good and evil because they are amoral. This does not mean that they are unethical (basically, immoral), or that they resulted from efforts to break moral norms, which are effective in society. The amorality of sports activity comes from the supremacy of legal regulations of a particular discipline (as it is clearly presented in the Norwegian case), and the priority of its legal context over the relativistic and discretionary moral demands.

2. It abolishes ethical paternalism with regard to adults, i.e. the norms which forbid our treating our own bodies according to our own needs, aspirations, and expectations. Moreover, in competitive, professional, spectator, and Olympic sport, a human body and its health (including mental and social health), is not considered and applied as an entity with an intrinsic value as an end-in-itself (as it is treated in participation in sports activities for the masses). Treating adult sportsmen in a paternalistic or penalizing way only because they dispose of their own bodies at their own discretion, seems to be neither necessary nor legitimate in terms of law and morality. Even making adults partially legally incapacitated with respect to the free disposal of their own bodies - in the context of thoughtful tolerance, and leaving aside moral and legal rigorism in relation to average people versus eminent artists - may or should evoke more or less legitimate objection.

Various representative artists, who stimulated themselves with different banned substances, particularly drugs, are often treated with a healthy dose of societal understanding. This pertains to, for example, Vincent van Gogh, Stanisław Ignacy Witkiewicz, Stanisław Przybyszewski (and other representatives of European, artistic bohemia from Modernism and Young Poland modernist period), or Andy Warhol. It also regards 20-something-year-old victims of drugs such as Jim Hendrix, Janis Joplin, Jim Morison (the lead singer of the Doors), Brian Jones (from the Rolling Stones), as well as Amy Winehouse, who was taking drugs for many years and recently died from an overdose. The former boxer and eminent film director, John Huston, alcoholized himself for many years. Bob Dylan and the Beatles were implicitly promoting - at the time of their highest popularity, the 1960s - drug use. An example is Bob Dylan's song Mr. Tambourine Man, in which the author suggested in suggestive way, comprehensible only to those who are thus initiated, that the tambourine man is a secret drug dealer. Other examples are to be found in the lines of Beatles' songs such as Lucy in the Sky with Diamonds (it refers to LSD) and Yellow Submarine.

Furthermore, the Yellow Submarine has become the most characteristic symbol of Liverpool: a huge effigy was placed in front of an entrance to the airport, while city tours are organized in small Yellow Submarine Buses. River trips in small yellow boats are charmingly named Yellow Duck Marine and sail around the river port.

3. This ethical paternalism and the penalization connected with it, does not pertain to - which is right - adults, because adults are aware of their own actions and should have a right to dispose of their own bodies. Moreover, it also concerns forms of - more or less harmful to health - 
sports activity on the highest level. For example, volleyball players and their coaches continue their careers despite being aware of the health risks of their professional sport. Robert Śmigielski, a traumatologist and orthopedist, the director of the medical team of the Polish Olympic Committee (PKOL), claims that

"Achilles tendons and ankle joints are the most vulnerable, then knee joints with the quadriceps femoris, spine, and shoulder running the most risk. 99.9\% of present volleyball stars will come to the doctor with injuries of these body parts" (Iwańczyk 2011, p. 38).

He regrets that the most well known players are exploited to the maximum, and he doubts the profitability of being

"a celebrity for the money they earn. Despite everything, this is a too low price for the damaged Achilles tendons, knees, and spine after the end of the career" (ibid.).

He states that

"he knows a few such patients who may be at risk of having a knee replacement or they can barely get up from a chair, and are thinking whether their career was worth that all" (ibid.).

The main purpose of such kind of activity is certainly not connected with cultivating any intrinsic values but is broadly understood sport success. Fitness of mind and body as well as variously defined health, play only an instrumental role in this sport. Moral, religious, political, or ideological convictions may have only additive and minor overtones provided that they prove to be favorable for realizing the basic purpose of competition.

Doping has the same significance, assumption, and aim, i.e. making use of the possibilities and reserves of energy hidden in a human body to the maximum. It may contribute to sports success in a different manner than an excessive optimization of physical training.

The consideration over the banned doping in the context of high and damaging exploitation of young competitors' bodies, which practice competitive, high level, professional, spectator, or Olympic sport, has overtones of false altruism and hypocritical care.

The legalization of doping would help to avoid such situations as in Norwegian cross-country skiing, in which there is pharmacological crypto-doping that is officially approved by the international sports associations and anti-drug institutions, and is supported by the Norwegian legislation and authorities.

I agree with Verner Moller, who indicates that the most common arguments against doping are its alleged entirely anti-health properties. Meanwhile, he writes, the sugars, salts, vitamins, and minerals contained in it, have a positive influence on the human body $(2010$, p. 107). This obviously challenges the legitimacy of the traditionally negative attitude towards doping. Also, it has occurred that (the above mentioned) alleged doping, or crypto-doping, based on antiasthmatic pharmaceutical drugs, also does not have a negative effect on the human organism.

Moller emphasizes that no final definition has been formulated to describe what doping is (in my opinion, such a definition will never take shape in its final form); that the institutions established in order to do this are unable to conduct a harmonious, consequent, logical antidoping campaign as well as to provide an adequate justification for it (2010, p. 107).

Moreover, it is a fact that there is a deficit, a lack of complete knowledge about the properties of doping. This pertains to its greatly diversified, positive and negative, influence on a human body. What is also noticeable is the oftentimes hardly significant, when all is said and done, influence doping has on health in comparison with the harmfulness of super-intensive training, increased exhaustive fights, matches, races, and other forms of competition. They cause and consolidate psychological, social, and physical destruction of the contestant. They ruin his/her health permanently and too frequently wreck his/her organism. All this, and I take into account not only the content covered in point 3 of this text, prevents the creation of a coherent anti-doping context of moral 
justification.

I am rather against making doping illegal, and particularly against substantiating this demand by referring to moral arguments. As far as I am concerned, the issue of doping should be settled by legal norms that apply to given communities, and then by the regulations of particular sports organizations and rules of individual disciplines. If doping (or crypto-doping) is not openly legalized by law, then it can be stated, without any relativist controversies, that a contestant who uses doping acts against the mentioned norms, rules, and regulations which provide for various forms of penalization. An appropriate committee of the sports club, organization, or sports federation specifies the nature and range of punishment for such violations. These sanctions are part of the legal order, as all activities within a particular professional sport (and related to sports regulations) must be institutionalized and accepted by a district court under code guiding administrative procedure. Therefore, in a way, the aforementioned penalization is indirectly sanctioned by the pertinent law in a particular country - that is, the administrative law. The direct sanction of national law - if one wishes to name it this way - can be identified as punishment resulting primarily from the rules guiding the code of criminal procedure, as, for example, in Italy. Athletes that use doping, as well as people associated with this phenomenon, are treated as offenders under the criminal code. If this kind of law applies to given communities, then breaching it can lead to moral sanctions, but this phenomenon is neither necessary nor common.

Ethical relativism neutralizes the possibility of applying any appropriately justified, indispensable, and universal ethical sanction, even in a form which establishes or supports the systematizing influence of legal jurisdiction.

Apart from that, what can be questioned is the need to regulate sports activity by means of legal regulations as well as implementing penalties. Perhaps Tamburini's thought should be taken to heart, as he believes that various social practices, among them sport, have a life of their own and often follow the paths which cannot and should not be, at least on first sight, restricted by law ("However, I believe that social practices, among them sports, have a life of their own and often develop in ways we cannot always judge, at least on first sight, as desirable", Tamburini, 2007, p. 33).

Nevertheless, I do not think that Tamburini's statement should be considered absolutely acceptable, especially in reference to competitive sports as well as championship, professional, spectator, or Olympic sports. Its numerous institutional representations in the form of national, supranational, continental, and international unions as well as the various sports events connected with them, should always be determined and organized in the context of binding legislation and its rules. These rules are characteristic of some specific disciplines and sports events such as the Olympic Games as well as world, continental, regional, national, or federal championship.

\section{REFERENCES}

Ajdukiewicz, K. (1985). Metodologiczne typy nauk /Methodological types of science/. In Język i poznanie /Language and cognition/ (pp. 287-213). Warsaw: PWN.

Allison, L. (2001). Amateurism in Sport: An Analysis and a Defense. London: Frank Cass.

Bertalanffy, von L. (1973). General System Theory. New York: George Braziller.

Butcher, R. and Schneider, A. (2007). Fair Play as Respect for the Game. In W.J. Morgan (Ed.), Ethics in Sport (pp. 119-140). Champaign, IL: Human Kinetics.

Digiel, H. (2004). The Principle of Fair Play - Why doping must never be allowed. Academic Supplement of Fair Play! The Official Publication of the European Fair Play Movement, 2, 6-8.

Donskis, L. (2005). Fair Play and the Legacy of Don Quixote. Academic Supplement of Fair Play! The Official Publication of the European Fair Play Movement, 4, 4-5.

Eliade, M. (1997). W poszukiwaniu historii $i$ znaczenia religii /The quest: history and meaning in religion/. Warszawa: Wydawnictwo KR.

Hegel, G.W.F. (1990). Encyklopedia nauk filozoficznych /Encyclopedia of the Philosophical Sciences/ (p. 258). Warszawa: PWN.

Heidegger, M. (1994). Bycie i czas /Being and time/ (p. 601). Warszawa: PWN. 
Iwańczyk, R. (2011). Śmigielski: Siatkarze jadą po bandzie/Śmigielski: Volleyball players are going full bore/. Gazeta Wyborcza, 292, p. 38.

Gilberg, R., Breivig, G. \& Loland, S. (2007). Anti-doping in Sport: The Norwegian Perspective. In A.J. Schneider and Fan Hong (Eds.), Doping in Sport. Global Ethical Issues (pp. 158-177). New York and London: Routledge.

Kant, I. (1984a). Krytyka praktycznego rozumu/The critique of practical reason/. Warszawa: PWN.

Kant, I. (1984b). Uzasadnienie metafizyki moralności /The groundwork of the metaphysics of morals/. Warszawa: PWN.

Kartezjusz (1981). Rozprawa o metodzie /The discourse on the method/. Warszawa: PWN.

Keating, J.W. (1964). Sportsmanship As a Moral Category. Ethics: An International of Social, Political, and Legal Philosophy, LXXV, 25-35.

Keating, J.W. (2001). Sportsmanship As a Moral Category. In W.J. Morgan, K.V. Meier, A.J. Schneider (Eds.), Ethics in Sport (pp. 7-20). Champain, IL: Human Kinetics.

Keating, J.W. (2007). Sportsmanship As a Moral Category. In W.J. Morgan (Ed.), Ethics in Sport (pp. 141-152). Champain, IL: Human Kinetics.

Kosiewicz, J. (1998). Eliade wobec przedustawnego uniwersum religii /Eliade and the pre-established universum of religion/. Kwartalnik Filozoficzny/Philosophical Quarterly/, 26(2), 277-283.

Kosiewicz, J. (1999). Bóg i afirmacja, czyli o pewności istnienia Boga /God and the affirmation: the certainty of God's existence/. In J. Kosiewicz, Bóg, cielesność i miłość /God, corporality, and love/ (pp. 13-38). Warszawa: Fundacja Aletheia.

Kosiewicz, J. (2005). Is the Principle of Fair Play the Highest Value in Sport? In J. Kosiewicz, Sport, Culture and Society (pp. 363-370). Warsaw: AWF.

Kosiewicz, J. (2008/2009). Philosophy of Sport from the Institutional, Content Related and Methodological Viewpoint. Physical Culture and Sport. Studies and Research, 46, 30-38. DOI: 10.2478/v10141-009-0001-5.

Kosiewicz, J. (2009). Prolegomena for Consideration on Western Sport and Spiritualism. Physical Culture and Sport. Studies and Research, 47, 79-88. DOI: 10.2478/v10141-009-0034-9.

Kosiewicz, J. (2010a). Physical Recreation in the Mirror of Philosophy. In J. Kosiewicz, Sport and Philosophy: From Methodology to Ethics (pp. 192-214). Warsaw: Wydawnictwo BK.

Kosiewicz, J. (2010b). Sport Beyond Moral Good and Evil. Physical Culture and Sport. Studies and Research, 49, 30-38. DOI: 10.2478/v10141-010-0012-2.

Kosiewicz, J. (2010c). Free Time from the Perspective of Ontology and Epistemology of Time. In J. Kosiewicz, Sport and Philosophy: From Methodology to Ethics (pp. 166-191). Warsaw: Wydawnictwo BK.

Kosiewicz, J. (2011). Foul Play in Sport as Phenomenon Inconsistent with the Rules, yet Acceptable and Desirable. Physical Culture and Sport. Studies and Research, 52, 33-43. DOI: 10.2478/v10141-011-0012-x.

Kretchmar, R.S. (2005). Ethics, Value Choices, and the Good Life. In Practical Philosophy of Sport and Physical Activity. Champaign, IL: Human Kinetics.

Leahy, F. (1951). Defensive Football. New York: Alfred A. Kopf, Inc.

Loland, S. (2002). Fair play: historical anachronism or topical ideal. In M.J. McNamee and S.J. Parry (Eds.), Ethics \& Sport. London and New York: Spon Press. Taylor \& Francis Group.

Loland, S. (2002). Fair play in Sport: A Moral Sport System. London \& New York: Routledge.

MacIntyre, A. (1996). Dziedzictwo cnoty. Studium z teorii moralności /After Virtue: A Study in Moral Theory/. Warszawa: Wydawnictwo Naukowe PWN.

McNamee, M. (2009). Beyond Consent? Paternalism and Pediatric Doping. Journal of the Philosophy of Sport, XXXVI, 2, 111-126.

Moller, V. (2010). Legislation of doping. In The Ethics of Doping and Anty-Doping (pp. 107-122). London and New York: Routlege. Taylor \& Francis Group.

Morgan, W.J. (2006). Why sports morally matter. New York and London: Routledge.

Morgan, W.J. (2007). Fair is Fair, Or Is It?: A Moral Consideration of the Doping Wars in American Sport. In A.J. Schneider and Fan Hong (Eds.), Doping in Sport. Global Ethical Issues (pp. 1-22). New York and London: Routledge.

Nietzsche, F. (1912). Poza dobrem i złem /Beyond good and evill. Warszawa - Kraków: Nakład Jakóba Mortkowicza.

Ossowska, M. (1966). Podstawy nauki o moralności /Foundations of the science of morality/. Warsaw: PWN.

Palm, J. (2004). Sport for All! - Fair Play for All? Academic Supplement of Fair Play! The Official Publication 
of the European Fair Play Movement, 1, 1-2.

Przyłuska-Fiszer, A., Misiuna, B. (1993). Etyczne aspekty sportu /Ethical aspects of sport/ (pp. 7-91). Warsaw: Wydawnictwo AWF.

Renson, R. (2005). Fair Play, fair Game, liar Game, fair Pay: Ethics versus Rhetoric in Sport and Society. Academic Supplement of Fair Play! The Official Publication of the European Fair Play Movement, 4.

Schneider, A.J. and Fan Hong (2007). Introduction. In A.J. Schneider and Fan Hong (Eds.), Doping in Sport. Global Ethical Issues (pp. XII-XXI). New York and London: Routledge.

Tamburini, C. (2007). Are doping Sanctions Jusified? A moral Relativistic View. In A.J. Schneider and Fan Hong (Eds.), Doping in Sport. Global Ethical Issues (pp. 23-35). New York and London: Routledge.

AUTHOR'S ADDRESS:

Jerzy Kosiewicz

Department of Philosophy, Chair of the Social Sciences

Josef Pilsudski University of Physical Education in Warsaw

34 Marymoncka str., 00-968 Warsaw, Poland

Email: jerzy.kosiewicz@awf.edu.pl 